Journal of Advanced Research in Fluid Mechanics and Thermal Sciences

Journal homepage: www.akademiabaru.com/arfmts.html ISSN: 2289-7879

\title{
Axisymmetric Hybrid Nanofluid Flow Due to a Convectively Heated Stretching/Shrinking Disk
}

\author{
Najiyah Safwa Khashi'ie ${ }^{1,{ }^{*}}$, Iskandar Waini ${ }^{1}$, Ioan Pop ${ }^{2}$, Nurul Amira Zainal ${ }^{1}$, Abdul Rahman Mohd \\ Kasim $^{3}$
1 Fakulti Teknologi Kejuruteraan Mekanikal dan Pembuatan, Universiti Teknikal Malaysia Melaka, Hang Tuah Jaya, 76100 Durian Tunggal, Melaka, Malaysia
2 Department of Mathematics, Babeş-Bolyai University, R-400084 Cluj-Napoca, Romania
3 Centre for Mathematical Sciences, College of Computing \& Applied Sciences, Universiti Malaysia Pahang, Lebuhraya Tun Razak, Gambang 26300, Pahang, Malaysia

\section{ARTICLE INFO
ABSTRACT}

$\begin{array}{ll}\begin{array}{l}\text { Article history: } \\ \text { Received } 26 \text { April } 2021\end{array} & \begin{array}{l}\text { This significant study is designed to analyze the axisymmetric hybrid nanofluid flow } \\ \text { with heat transfer on a convectively heated stretching/shrinking disk. The combination } \\ \text { Received in revised form } 20 \text { June } 2021\end{array} \\ \begin{array}{l}\text { Accepted } 3 \text { July } 2021 \\ \text { of metal }(\mathrm{Cu}) \text { and metal oxide }\left(\mathrm{Al}_{2} \mathrm{O}_{3}\right) \text { nanoparticles with water }\left(\mathrm{H}_{2} \mathrm{O}\right) \text { as the base fluid } \\ \text { is used for the analysis. Similarity transformation is adopted to reduce the complexity } \\ \text { of the PDEs into a system of ODEs. The utilization of suction in maintaining the steady } \\ \text { flow solution for the shrinking disk case discloses the presence of dual solutions. }\end{array} \\ \begin{array}{l}\text { feywords: } \\ \begin{array}{l}\text { Convective boundary condition; Dual } \\ \text { solutions; Hybrid nanofluid; Stability }\end{array}\end{array} \\ \begin{array}{l}\text { Besides, an upsurge of Biot number and suction's strength enhances the heat transfer } \\ \text { onalysis }\end{array}\end{array}$

\section{Introduction}

Hybrid nanofluids are widely used in the experimental and numerical investigations of fluid dynamics due to its significance in the thermal and energy performances. The composite/hybrid nanoparticles are developed from two types of nanoparticles: metal oxides (i.e., $\mathrm{Al}_{2} \mathrm{O}_{3} /$ alumina, $\mathrm{CuO} /$ cupric oxide, $\mathrm{Fe}_{3} \mathrm{O}_{4}$ /magnetite, $\mathrm{Fe}_{2} \mathrm{O}_{3}$ /hematite), metals (i.e., Ag/silver, $\mathrm{Cu} / \mathrm{copper}$ ), carbon materials (i.e., CNT/carbon nanotube, graphite, MWCNT/multi-walled carbon nanotubes) or metal carbide. Idris et al., [1] examined the heat transfer performance of alumina-silica/water nanofluid in cooling plate of PEMFC (Proton Electrolyte Membrane fuel cells) which is applicable for the automotive industry. The brief discussion on the preparation, stability, recent applications, and thermal conductivity of the hybrid and single nanofluids can be found from the review papers by Halim and Sidik [2,3], Sidik et al., [4], Babu et al., [5] and Sajid and Ali [6]. Suresh et al., [7] highlighted the advantages of the $\mathrm{Cu}-\mathrm{Al}_{2} \mathrm{O}_{3}$ hybrid nanoparticle which then led to the proposal of thermophysical

\footnotetext{
* Corresponding author.

E-mail address: najiyah@utem.edu.my

https://doi.org/10.37934/arfmts.85.1.113124
} 
properties' correlations for hybrid nanofluids by Devi and Devi [8]. They used these correlations to analyze a steady boundary layer flow problem due to a stretching sheet.

Another correlations of hybrid nanofluids which were proposed by Takabi and Salehi [9] have been widely used in the numerical simulation of fluid motion. There is only a slight of difference between the numerical values using both correlations as discussed by Xu [10] and Khashi'ie et al., [11]. A detail comparison of the published papers with different types of correlations was initiated and discussed by Khashi'ie et al., [12]. The numerical exploration of dual solutions in hybrid nanofluid flow is not only limited to a flat plate surface, but also have been actively investigated for a thin needle, circular cylinder, disk, Riga plate and curved surface [11-31].

Inspired by the capability of hybrid nanofluids in enhancing the heat transfer operation, this work is devoted to (i) discover the control parameters which can delay the separation of fluid motion and enhance the heat transfer operation, and (ii) to observe the non-unique solutions and the solutions' stability for a hybrid nanofluid flow on a convectively heated stretching/shrinking disk. The hybrid $\mathrm{Cu}-\mathrm{Al}_{2} \mathrm{O}_{3} /$ water nanofluid with the correlations by Takabi and Salehi [9] are used in this work. We are confident that this study is novel and new for a disk geometry which significantly can help other researchers in examining the hybrid nanofluid motion with heat transfer. However, the future findings are only conclusive to the pair of this hybrid nanoparticle.

\section{Problem Formulation}

Consider an axisymmetric flow of hybrid nanofluid over a permeable stretching/shrinking disk with convective boundary condition (CBC). The hybrid nanoparticles from metal ( $\mathrm{Cu}$ ) and metal oxide $\left(\mathrm{Al}_{2} \mathrm{O}_{3}\right)$ groups are modeled with the water $\left(\mathrm{H}_{2} \mathrm{O}\right)$ base fluid using the applicable correlations of hybrid nanofluid proposed by Takabi and Salehi [9]. For the geometry of the problem as exhibited in Figure 1 , cylindrical coordinate $(r, \alpha, z)$ is used with the fluid motion on the plane $z=0$. The stretching/shrinking disk is moved with a linear velocity $u_{w}(r)=a r$ where $a$ is a constant. The bottom of the disk is convectively heated from the hybrid nanofluid with a fixed temperature $T_{f}$ and a heat transfer coefficient $h_{f}$. Meanwhile the constant ambient temperature is represented by $T_{\infty}$.

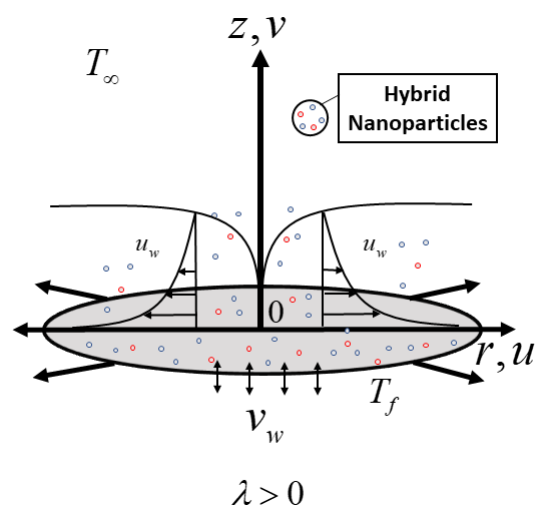

(a) Stretching disk

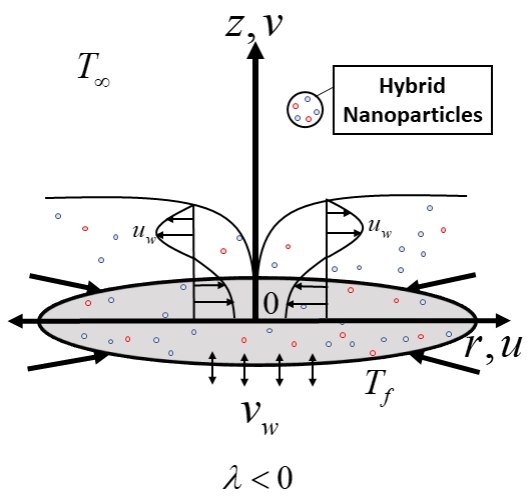

(b) Shrinking disk

Fig. 1. The physical model

With the consideration of the boundary layer approximations, the mathematical model in the form of partial differential equations is $[11,29]$ 


$$
\begin{aligned}
& \frac{\partial(r u)}{\partial r}+\frac{\partial(r v)}{\partial z}=0, \\
& u \frac{\partial u}{\partial r}+v \frac{\partial u}{\partial z}=\frac{\mu_{h n f}}{\rho_{h n f}} \frac{\partial^{2} u}{\partial z^{2}}, \\
& u \frac{\partial T}{\partial r}+v \frac{\partial T}{\partial z}=\frac{k_{h n f}}{\left(\rho C_{p}\right)_{h n f}} \frac{\partial^{2} T}{\partial z^{2}},
\end{aligned}
$$

subject to the boundary conditions $[16,29]$

$$
\begin{aligned}
& u=\lambda u_{w}(r), \quad v=v_{w}, \quad-k_{h n f} \frac{\partial T}{\partial z}=h_{f}\left(T_{f}-T\right), \\
& u \rightarrow 0, \quad T \rightarrow T_{\infty}, \quad \text { as } \quad z \rightarrow \infty .
\end{aligned}
$$

where $v_{w}=-S \sqrt{a v_{f}}$ is the mass flow with $v_{w}<0$ stands for suction and $v_{w}>0$ denotes the injection process. The hybrid nanofluid velocities are represented by $u$ ( $r$-direction) and $v$ ( $z$-direction), while $T$ is the hybrid nanofluid temperature. The thermophysical properties of hybrid nanofluid used in this work are presented in Table 1. It is worth to mention that these correlations are introduced by Takabi and Salehi [9] which can be reduced to a case of nanofluid if $\phi_{1}=0$ or $\phi_{2}=0$. Nonetheless, these correlations are applicable to a pure water (viscous fluid) model if $\phi_{1}, \phi_{2} \approx 0$. It is worth to point out that the total concentration of the hybrid nanoparticles is denoted as $\phi_{h n f}=\phi_{1}+\phi_{2}$.

Table 1

The thermophysical properties between hybrid and traditional nanofluid [9]

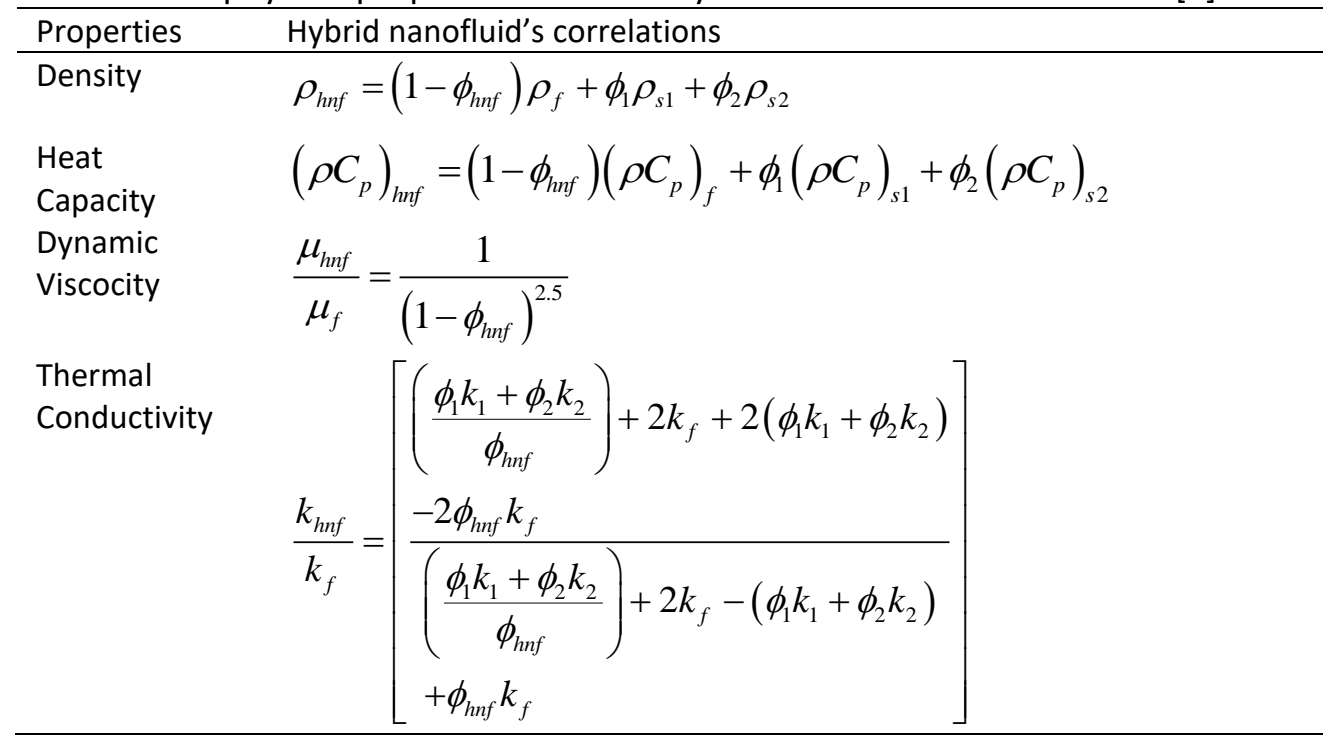

From Table 1, $\phi_{1}$ and $\phi_{2}$ denote the volumetric concentration of the $\mathrm{Al}_{2} \mathrm{O}_{3}$ and $\mathrm{Cu}$ nanoparticles, respectively, the subscripts $s 1, s 2, h n f, n f$ and $f$ represent the $\mathrm{Al}_{2} \mathrm{O}_{3}$ nanoparticle, Cu nanoparticle, hybrid nanofluid, nanofluid and base fluid, accordingly. For the numerical exploration, the thermophysical properties of the $\mathrm{Al}_{2} \mathrm{O}_{3}$ nanoparticle, $\mathrm{Cu}$ nanoparticle and pure water are used and listed in Table 2. 
Table 2

Thermophysical properties of the $\mathrm{Al}_{2} \mathrm{O}_{3}, \mathrm{Cu}$ and $\mathrm{H}_{2} \mathrm{O}$ [32]

\begin{tabular}{llll}
\hline Thermophysical properties & $\rho\left(\mathrm{kg} / \mathrm{m}^{3}\right)$ & $C_{p}(\mathrm{~J} / \mathrm{kgK})$ & $k(\mathrm{~W} / \mathrm{mK})$ \\
\hline $\mathrm{Al}_{2} \mathrm{O}_{3}$ & 3970 & 765 & 40 \\
$\mathrm{Cu}$ & 8933 & 385 & 400 \\
$\mathrm{H}_{2} \mathrm{O}$ & 997.1 & 4179 & 0.6130 \\
\hline
\end{tabular}

The complexity of Eq. (2)-(4) is reduced by applying the similarity transformation in Eq. (5). This transformation can be adopted if and only if it fulfils Eq. (1) and for this problem $[16,29]$,

$u=\operatorname{arf}^{\prime}(\eta), \quad v=-2 \sqrt{a v_{f}} f(\eta), \quad \theta(\eta)=\frac{T-T_{\infty}}{T_{f}-T_{\infty}}, \quad \eta=z \sqrt{\frac{a}{v_{f}}}$.

The reduced similarity equations are then, given by

$\left(\frac{\mu_{h n f} / \mu_{f}}{\rho_{h n f} / \rho_{f}}\right) f^{\prime \prime \prime}+2 f f^{\prime \prime}-f^{\prime 2}=0$,

$\frac{1}{\operatorname{Pr}} \frac{k_{h n f} / k_{f}}{\left(\rho C_{p}\right)_{h n f} /\left(\rho C_{p}\right)_{f}} \theta^{\prime \prime}+2 f \theta^{\prime}=0$

inclusive of the boundary conditions [16]

$f(0)=S, \quad f^{\prime}(0)=\lambda, \quad \frac{-k_{h n f}}{k_{f}} \theta^{\prime}(0)=B i[1-\theta(0)]$,

$f^{\prime}(\eta) \rightarrow 0, \quad \theta(\eta) \rightarrow 0, \quad$ as $\quad \eta \rightarrow \infty$

where $\operatorname{Pr}=\frac{\mu_{f}\left(C_{p}\right)_{f}}{k_{f}}$ is the Prandtl number where $\operatorname{Pr}=6.2$ represents water, $B i=\frac{h_{f}}{k_{f}} \sqrt{\frac{v_{f}}{a}}$ is the Biot number and $S$ is the suction/injection parameter.

The skin friction coefficient with the local Nusselt number, are mathematically expressed by

$C_{f}=\frac{2 \tau_{w}}{\rho_{f} u_{w}^{2}}, \quad N u_{r}=\frac{r q_{w}}{k_{f}\left(T_{f}-T_{\infty}\right)}$,

where $\tau_{w}$ and $q_{w}$ are the shear stress and heat flux of the surface/heated disk, respectively

$\tau_{w}=\mu_{h n f}\left(\frac{\partial u}{\partial z}\right)_{z=0}, q_{w}=-k_{h n f}\left(\frac{\partial T}{\partial z}\right)_{z=0}$.

With the substitution of (5) and (10) into (9), the reduced skin friction coefficient and heat transfer rate are respectively given by 
$0.5 \operatorname{Re}_{r}^{1 / 2} C_{f}=\frac{\mu_{h n f}}{\mu_{f}} f^{\prime \prime}(0), \operatorname{Re}_{r}^{-1 / 2} N u_{r}=-\frac{k_{h n f}}{k_{f}} \theta^{\prime}(0)$,

where $\operatorname{Re}_{r}=\frac{r u_{w}}{v_{f}}$.

\section{Stability Analysis}

There are a few of steps in the implementation of stability analysis which are,

i. consider the unsteady form of Eq. (2) and Eq. (3) as suggested by Merkin [33]

$\frac{\partial u}{\partial t}+u \frac{\partial u}{\partial r}+v \frac{\partial u}{\partial z}=\frac{\mu_{h n f}}{\rho_{h n f}} \frac{\partial^{2} u}{\partial z^{2}}$

$\frac{\partial T}{\partial t}+u \frac{\partial T}{\partial r}+v \frac{\partial T}{\partial z}=\frac{k_{h n f}}{\left(\rho C_{p}\right)_{h n f}} \frac{\partial^{2} T}{\partial z^{2}}$

with a new set of similarity transformations including the dimensionless time variable $\tau$

$u=\operatorname{ar} \frac{\partial f(\eta, \tau)}{\partial \eta}, \quad v=-2 \sqrt{a v_{f}} f(\eta, \tau), \quad \theta(\eta, \tau)=\frac{T-T_{\infty}}{T_{f}-T_{\infty}}, \quad \eta=z \sqrt{\frac{a}{v_{f}}}, \quad \tau=a t$.

By substituting Eq. (14) into Eq. (12) and Eq. (13), the transformed equations are

$\left(\frac{\mu_{h n f} / \mu_{f}}{\rho_{\text {hnf }} / \rho_{f}}\right) \frac{\partial^{3} f}{\partial \eta^{3}}+2 f \frac{\partial^{2} f}{\partial \eta^{2}}-\left(\frac{\partial f}{\partial \eta}\right)^{2}-\frac{\partial^{2} f}{\partial \eta \partial \tau}=0$,

$\frac{1}{\operatorname{Pr}} \frac{k_{h n f} / k_{f}}{\left(\rho C_{p}\right)_{h n f} /\left(\rho C_{p}\right)_{f}} \frac{\partial^{2} \theta}{\partial \eta^{2}}+2 f \frac{\partial \theta}{\partial \eta}-\frac{\partial \theta}{\partial \tau}=0$,

with the transformed conditions

$f(0, \tau)=S, \quad \frac{\partial f(0, \tau)}{\partial \eta}=\lambda, \quad \frac{-k_{h n f}}{k_{f}} \frac{\partial \theta(0, \tau)}{\partial \eta}=B i[1-\theta(0, \tau)]$,

$\frac{\partial f(\eta, \tau)}{\partial \eta} \rightarrow 0, \quad \theta(\eta, \tau) \rightarrow 0, \quad$ as $\quad \eta \rightarrow \infty$.

ii. use the perturbation equations to test the solutions' stability. The perturbation equations are given by [34]

$\left.f(\eta, \tau)=f_{0}(\eta)+e^{-\gamma \tau} F(\eta)\right\}$

$\left.\theta(\eta, \tau)=\theta_{0}(\eta)+e^{-\gamma \tau} H(\eta)\right\}$ 
where $f(\eta)=f_{0}(\eta)$ and $\theta(\eta)=\theta_{0}(\eta), \gamma$ is an unknown eigenvalue whereas $F(\eta)$ and $H(\eta)$ are a small relative to $f_{0}(\eta)$ and $\theta_{0}(\eta)$, respectively. Hence, by inserting Eq. (18) into Eq. (15)-(17), the linearized eigenvalue problem is

$$
\begin{aligned}
& \frac{\mu_{h n f} / \mu_{f}}{\rho_{h n f} / \rho_{f}} F^{\prime \prime \prime}+2 f_{0} F^{\prime \prime}-\left(2 f_{0}^{\prime}-\gamma\right) F^{\prime}+2 F f_{0}^{\prime \prime}=0, \\
& \frac{1}{\operatorname{Pr}} \frac{k_{h n f} / k_{f}}{\left(\rho C_{p}\right)_{h n f} /\left(\rho C_{p}\right)_{f}} H^{\prime \prime}+2 F \theta_{0}^{\prime}+2 f_{0} H^{\prime}+\gamma H=0,
\end{aligned}
$$

with

$$
\begin{aligned}
& F(0)=0, \quad F^{\prime}(0)=0, \quad F^{\prime \prime}(0)=1, \quad \frac{k_{h n f}}{k_{f}} H^{\prime}(0)=B i H(0), \\
& F^{\prime}(\eta) \rightarrow 0 \text { (relaxed), } \quad H(\eta) \rightarrow 0, \quad \text { as } \quad \eta \rightarrow \infty
\end{aligned}
$$

after considering the relaxation of boundary condition as implemented by Harris et al., [35]. The sign of the smallest eigenvalue $\gamma_{1}$ will determine the stability of solutions.

\section{Results and Discussions}

In this section, the numerical solutions are obtained by solving Eq. (6)-(8) using the bvp4c application in the Matlab software. The impact of the respective parameters namely suction $S$, Biot number $B i$ and the volumetric concentrations of the nanoparticles $\left(\phi_{1}, \phi_{2}\right)$ on the reduced skin friction coefficient and local Nusselt number/heat transfer rate are briefly discussed including the analysis of solutions' stability. For this purpose, the values are chosen based on the main references and from the trial-and-error basis due to the existence of two solutions. As stated in Section 2, the value of Prandtl number is set as $\operatorname{Pr}=6.2$ which denotes the water base fluid at $25^{\circ} \mathrm{C}$. Meanwhile the values for other parameters are within these ranges $3 \leq S \leq 3.1,0.1 \leq B i \leq 0.102$ and $0 \leq \phi_{1}, \phi_{2} \leq 0.02$. Using the correlations of hybrid nanofluid by Takabi and Salehi [9], the total volumetric concentration of the $\mathrm{Cu}-\mathrm{Al}_{2} \mathrm{O}_{3}$ hybrid nanoparticles is $\phi_{h n f}=\phi_{1}+\phi_{2}$. The verification of model is conducted by comparing the values of $0.5 \operatorname{Re}_{r}^{1 / 2} C_{f}$ and $\operatorname{Re}_{r}^{-1 / 2} N u_{r}$ with Khashi'ie et al., [11] when $B i \rightarrow \infty$ (constant temperature condition), $\operatorname{Pr}=6.2$ and $\lambda=1$ as shown in Table 3 . The present numerical values are in accordance with the previous data, hence, justify the accuracy of the present bvp4c codes.

The stability of the solutions is obtained by solving Eq. (19)-(21) using the continuous code of Eq. (6)-(8) in the bvp4c solver. Table 4 presents the smallest eigenvalue $\gamma_{1}$ of the solutions towards $\lambda$. The positive sign of $\gamma_{1}$ for the first solution implies the reliability and stability of the solution while opposite result is obtained for the second solution. 


\section{Table 3}

Comparison values of $0.5 \operatorname{Re}_{r}^{1 / 2} C_{f}$ and $\operatorname{Re}_{r}^{-1 / 2} N u_{r}$ when $B i \rightarrow \infty, \operatorname{Pr}=6.2$ and $\lambda=1$

\begin{tabular}{lllllll}
\hline$S$ & $\phi_{1}$ & $\phi_{2}$ & \multicolumn{3}{c}{ Present } & \multicolumn{3}{c}{ Khashi'ie et al., [11] } \\
\cline { 4 - 7 } & & & $0.5 \operatorname{Re}_{r}^{1 / 2} C_{f}$ & $\operatorname{Re}_{r}^{-1 / 2} N u_{r}$ & $0.5 \operatorname{Re}_{r}^{1 / 2} C_{f}$ & $\operatorname{Re}_{r}^{-1 / 2} N u_{r}$ \\
\hline 0 & 0 & 0 & -1.17372 & 2.54642 & -1.17372 & 2.54642 \\
& 0 & 0.005 & -1.20437 & 2.55839 & -1.20437 & 2.55839 \\
& 0.005 & 0 & -1.18987 & 2.56044 & -1.18987 & 2.56044 \\
& 0.01 & 0.01 & -1.26788 & 2.59961 & -1.26788 & 2.59961 \\
2.1 & 0 & 0 & -4.52863 & 26.43654 & -4.52863 & 26.43654 \\
& 0 & 0.005 & -4.70055 & 26.41731 & -4.70055 & 26.41731 \\
& 0.005 & 0 & -4.59544 & 26.40581 & -4.59544 & 26.40581 \\
& 0.01 & 0.01 & -5.00649 & 26.33703 & -5.00649 & 26.33703 \\
\hline
\end{tabular}

Table 4

Smallest eigenvalue $\gamma_{1}$ when $S=\varepsilon=\delta=0$ and $\lambda=1$

\begin{tabular}{lll}
\hline$\lambda$ & $\gamma_{1}$ (First solution) & $\gamma_{1}$ (Second solution) \\
\hline-5.5168 & 0.0222 & -0.0221 \\
-5.5164 & 0.0782 & -0.0774 \\
-5.516 & 0.1085 & -0.107 \\
-5.51 & 0.3143 & -0.3017 \\
-5.5 & 0.4981 & -0.4671 \\
\hline
\end{tabular}

The values of $0.5 \operatorname{Re}_{r}^{1 / 2} C_{f}$ and $\operatorname{Re}_{r}^{-1 / 2} N u_{r}$ towards $\lambda$ when $\phi_{h n f}=0.02,0.025$ and 0.03 are presented in Figure 2(a) and Figure 2(b), respectively. The total of volumetric concentrations for hybrid $\mathrm{Cu}-\mathrm{Al}_{2} \mathrm{O}_{3}$ /water nanofluid is allocated from equal concentrations of alumina and copper nanoparticles where $\quad \phi_{h n f}=0.02\left(\phi_{1}, \phi_{2}=0.01\right), \quad \phi_{h n f}=0.025\left(\phi_{1}, \phi_{2}=0.0125\right) \quad$ and $\phi_{\text {hnf }}=0.03\left(\phi_{1}, \phi_{2}=0.015\right)$. From Figure 2, the dual solutions exist for given $\phi_{\text {hnf }}$ when $S=3$ and $B i=0.1$. An increase of $\phi_{h n f}$ extends $\left|\lambda_{c}\right|$ where $\lambda_{c}$ is the approximated separation value of the laminar flow. The first and second solutions meet at $\lambda_{c}$ and beyond this value, no solution exists. These findings also show that the high concentration of $\phi_{h n f}$ can slightly reduce the heat transfer rate of the working fluid. The performance of hybrid nanofluid in enhancing the heat transfer rate was affected using high suction strength $(S>2)$ [11,29]. Moreover, as $\lambda \rightarrow \lambda_{c}$, both skin friction coefficient and heat transfer rate of the hybrid $\mathrm{Cu}-\mathrm{Al}_{2} \mathrm{O}_{3} /$ water nanofluid marginally deteriorate, and these results are seen for all values of $\phi_{h n f}$. 


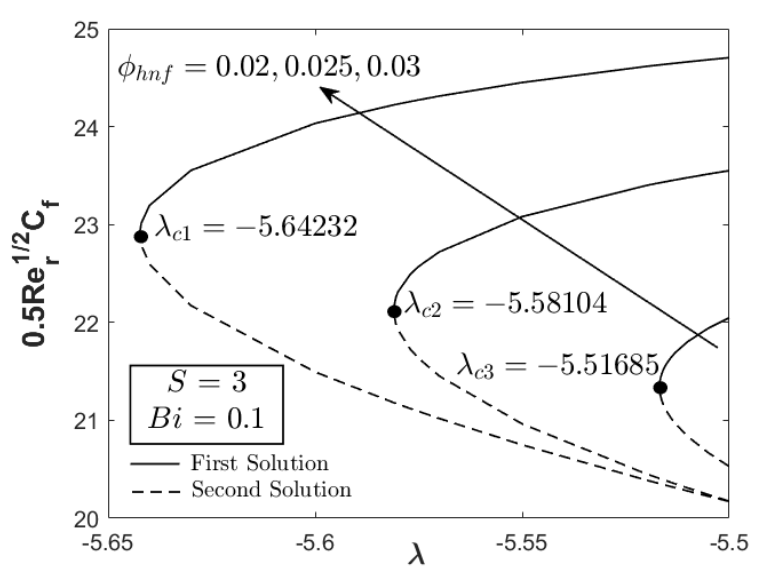

(a)

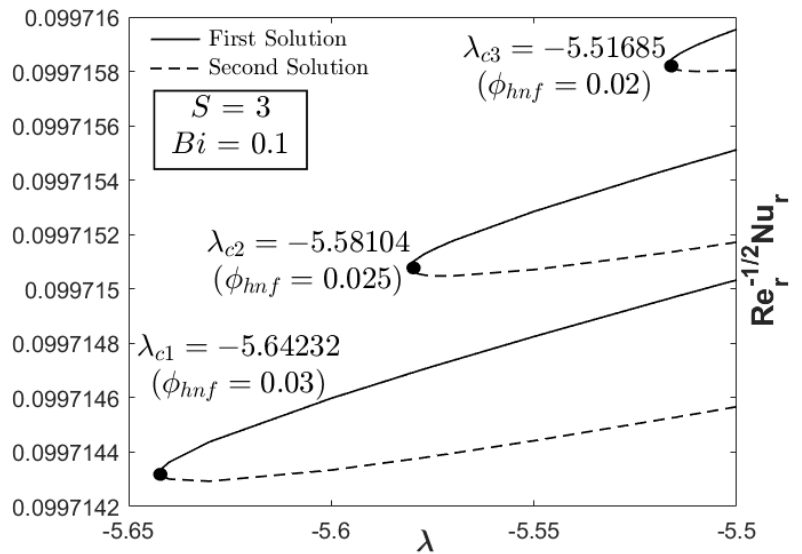

(b)

Fig. 2. The distribution of (a) $0.5 \operatorname{Re}_{r}^{1 / 2} C_{f}$, and (b) $\operatorname{Re}_{r}{ }^{-1 / 2} N u_{r}$ towards $\lambda$ for various $\phi_{h n f}$

The impact of suction on the skin friction coefficient and the heat transfer rate is portrayed in Figure 3(a) and Figure 3(b), respectively. An increase of suction's strength by $5 \%(S=3,3.05,3.1)$ enhances both $0.5 \operatorname{Re}_{r}^{1 / 2} C_{f}$ and $\operatorname{Re}_{r}^{-1 / 2} N u_{r}$. The suction parameter also delays the separation of boundary layer flow and this is seen from the extension of the separation point where $\lambda_{c}=-5.51685(S=3), \lambda_{c}=-5.70277(S=3.05)$ and $\lambda_{c}=-5.89076(S=3.1)$. Meanwhile, Figure 4 (a) demonstrate the effect of Biot number which represents the convective heat transfer process on the performance of the $\mathrm{Cu}-\mathrm{Al}_{2} \mathrm{O}_{3} /$ water nanofluid. As the Biot number slightly augments, the enhancement of heat transfer rate is seen. From Eq. (8), the Biot number is comparable with $-\theta^{\prime}(0)$ which implies the operation of convective heating process in regulating and augmenting the wall temperature as clearly exhibited in Figure 4(b).

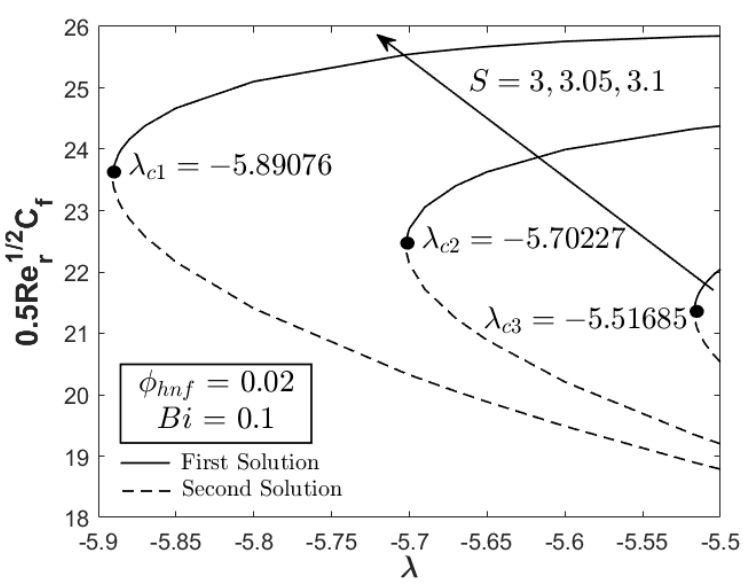

(a)

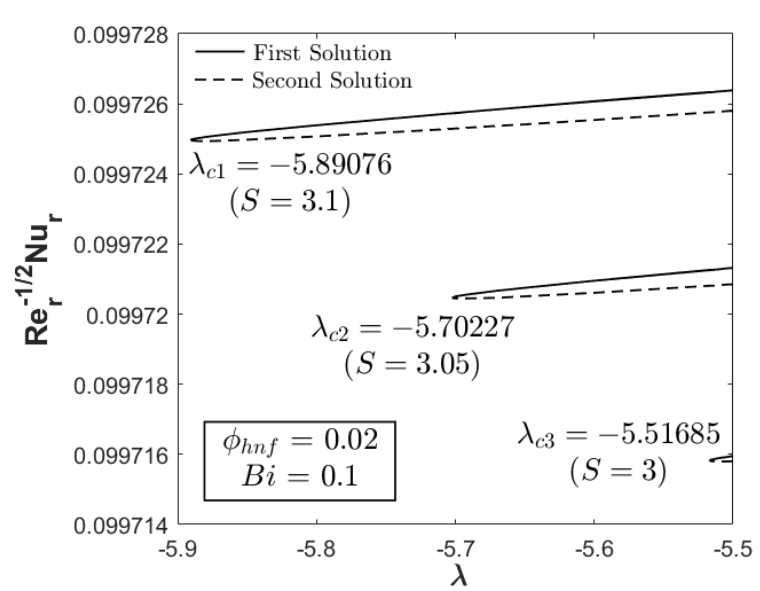

(b)

Fig. 3. The distribution of (a) $0.5 \operatorname{Re}_{r}^{1 / 2} C_{f}$, and (b) $\operatorname{Re}_{r}^{-1 / 2} N u_{r}$ towards $\lambda$ for various $S$ 


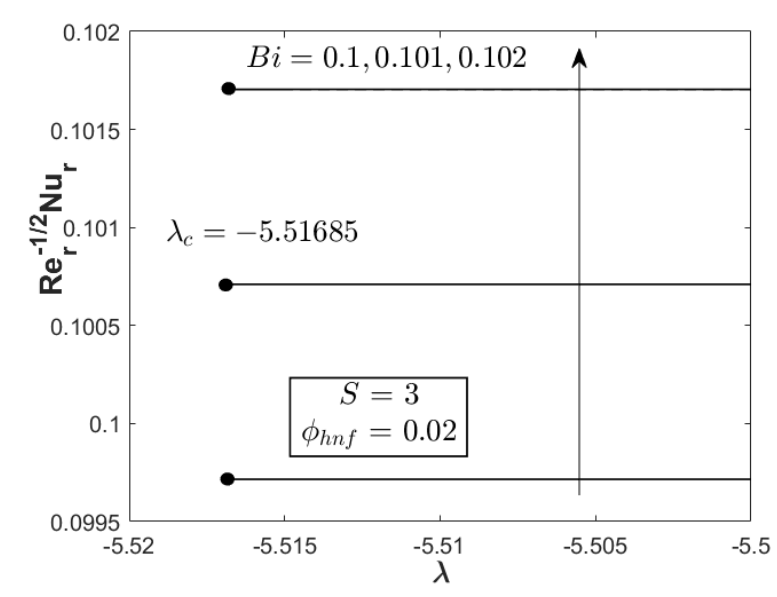

(a)

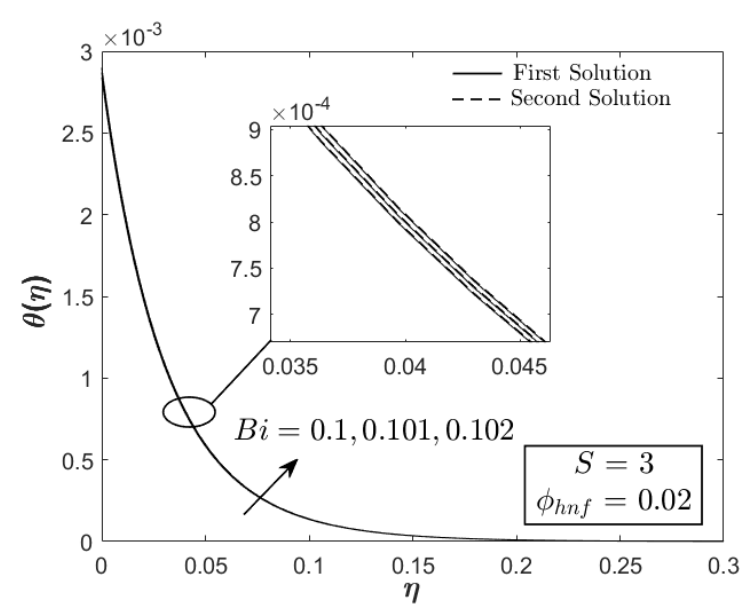

(b)

Fig. 4. The distribution of (a) $\operatorname{Re}_{r}^{-1 / 2} N u_{r}$ towards $\lambda$, and (b) temperature profile with various $B i$

Figure 5(a) and Figure 5(b) present the relationship between $\phi_{1}$ and $\phi_{2}$ on the distribution of $0.5 \mathrm{Re}_{r}^{1 / 2} C_{f}$ and $\operatorname{Re}_{r}^{-1 / 2} N u_{r}$. From Figure 5(a), the pure water $\left(\phi_{1}, \phi_{2}=0\right)$ has the lowest skin friction coefficient while the $\mathrm{Cu}-\mathrm{Al}_{2} \mathrm{O}_{3} /$ water nanofluid with $\phi_{1}=0.01$ and $\phi_{2}=0.02$ has the highest $0.5 \mathrm{Re}_{r}^{1 / 2} C_{f}$. As the volumetric concentrations for $\mathrm{Al}_{2} \mathrm{O}_{3}\left(\phi_{1}\right)$ and $\mathrm{Cu}\left(\phi_{2}\right)$ increase, the skin friction coefficient also increases. Surprisingly, the use of $\mathrm{Cu}-\mathrm{Al}_{2} \mathrm{O}_{3} /$ water nanofluid in this work does not contribute to the development of the heat transfer rate as it is evident from Figure $5(\mathrm{~b})$ that the pure water has the highest $\operatorname{Re}_{r}^{-1 / 2} N u_{r}$. Further observation shows that the addition of $\phi_{1}$ and $\phi_{2}$ reduce the heat transfer performance of the working fluid. However, it is worth to mention that this discussion is only valid for the case of shrinking sheet $(\lambda=-5.5)$. Figure $6(a)$ and Figure $6(b)$ display the profiles for velocity and temperature, respectively with different fluids where $b f, n f$ and $h n f$ stand for pure water $\left(\phi_{1}, \phi_{2}=0\right)$, Cu-water nanofluid $\left(\phi_{1}=0, \phi_{2}=0.01\right)$ and $\mathrm{Cu}-\mathrm{Al}_{2} \mathrm{O}_{3} /$ water nanofluid $\left(\phi_{1}, \phi_{2}=0.01\right)$, accordingly. Theoretically, the boost of $\phi_{1}$ and $\phi_{2}$ may generate energies within the fluid particles and then, potential to increase the velocity and temperature profile.

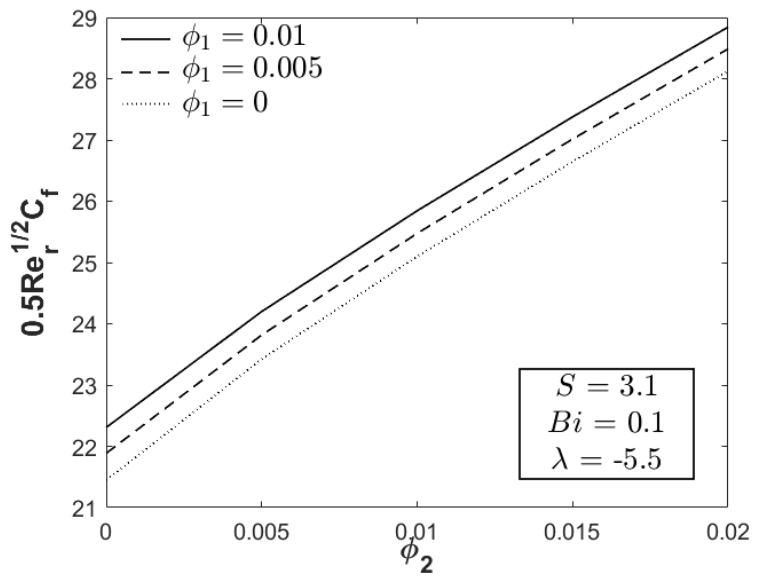

(a)

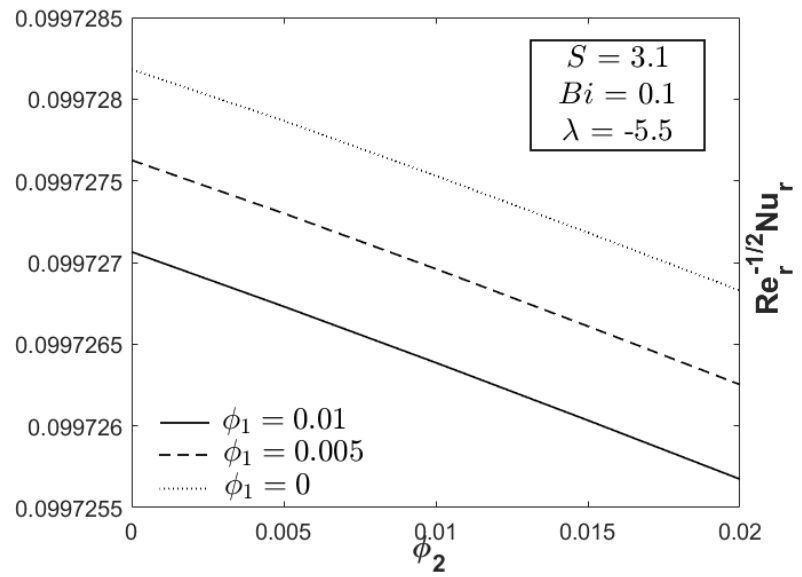

(b)

Fig. 5. The distribution of (a) $0.5 \operatorname{Re}_{r}^{1 / 2} C_{f}$, and (b) $\operatorname{Re}_{r}^{-1 / 2} N u_{r}$ towards $\phi_{2}$ for various $\phi_{1}$ 


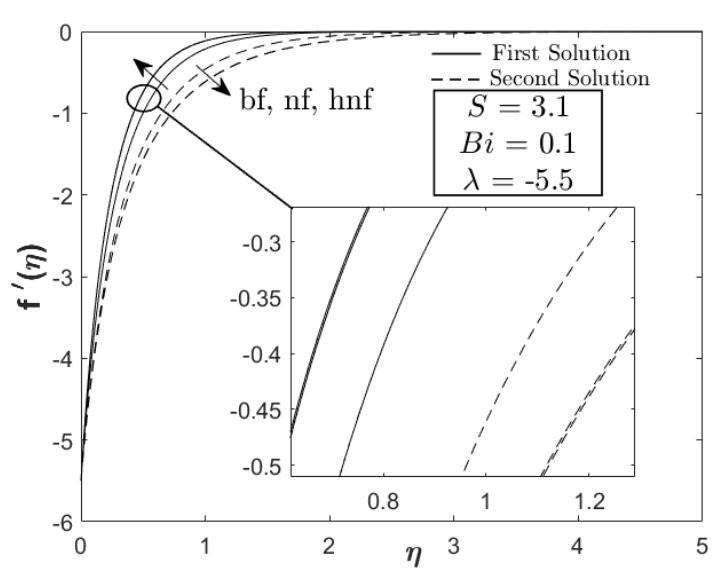

(a)

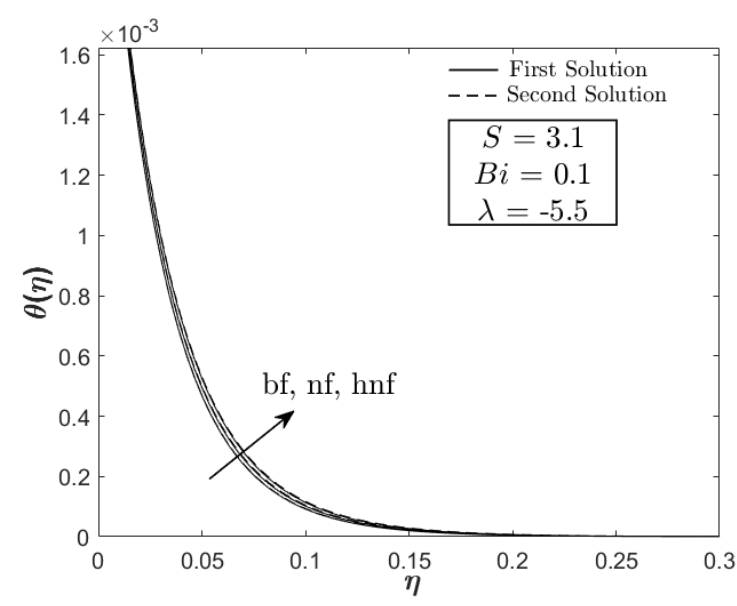

(b)

Fig. 6. (a) Velocity, and (b) temperature profiles for different fluids when $S=3.1, B i=0.1$ and $\lambda=-5.5$

\section{Conclusions}

The analysis of hybrid $\mathrm{Cu}-\mathrm{Al}_{2} \mathrm{O}_{3} /$ water nanofluid flow on a stretching/shrinking and permeable disk with convective boundary condition is conducted using the bvp4c solver. The thermophysical properties of hybrid nanofluid are evaluated numerically using the existing correlation and the results are evaluated within a certain range of the control parameters namely suction $S$, Biot number $B i$ and the volumetric concentrations of the nanoparticles $\left(\phi_{1}, \phi_{2}\right)$. The conclusions are

i. The separation of laminar flow can be delayed by enhancing the suction's strength and the hybrid nanoparticles volumetric concentration. This observation is based on the location of critical/separation value.

ii. The augmentation of heat transfer rate is seen for the addition of suction and Biot number.

iii. The stability analysis verifies the stability of the first solution.

iv. An increase of Biot number slightly increases the temperature profile of the $\mathrm{Cu}-\mathrm{Al}_{2} \mathrm{O}_{3} /$ water nanofluid.

v. The $\mathrm{Cu}-\mathrm{Al}_{2} \mathrm{O}_{3} /$ water nanofluid has higher distribution of the velocity and temperature profiles than the $\mathrm{Cu}$-water nanofluid and pure water.

\section{Acknowledgment}

The authors would like to acknowledge Universiti Teknikal Malaysia Melaka through the grant JURNAL/2019/FTKMP/Q00042.

\section{References}

[1] Idris, Muhammad Syafiq, Irnie Azlin Zakaria, and Wan Azmi Wan Hamzah. "Heat Transfer and Pressure Drop of Water Based Hybrid $\mathrm{Al}_{2} \mathrm{O}_{3}: \mathrm{SiO}_{2}$ Nanofluids in Cooling Plate of PEMFC." Journal of Advanced Research in Numerical Heat Transfer 4, no. 1 (2021): 1-13.

[2] Halim, Nur Fazlin Che, and Nor Azwadi Che Sidik. "Nanorefrigerants: A Review on Thermophysical Properties and Their Heat Transfer Performance." Journal of Advanced Research in Applied Sciences and Engineering Technology 20, no. 1 (2020): 42-50. https://doi.org/10.37934/araset.20.1.4250

[3] Halim, Nur Fazlin Che, and Nor Azwadi Che Sidik. "Mixing Chamber for Preparation of Nanorefrigerant." Journal of Advanced Research in Applied Sciences and Engineering Technology 21, no. 1 (2020): 32-40. https://doi.org/10.37934/araset.21.1.3240

[4] Sidik, Nor Azwadi Che, Isa Muhammad Adamu, Muhammad Mahmud Jamil, G. H. R. Kefayati, Rizalman Mamat, and G. Najafi. "Recent progress on hybrid nanofluids in heat transfer applications: a comprehensive review." 
International Communications in Heat and Mass Transfer $78 \quad$ (2016): 68-79. https://doi.org/10.1016/i.icheatmasstransfer.2016.08.019

[5] Babu, JA Ranga, K. Kiran Kumar, and S. Srinivasa Rao. "State-of-art review on hybrid nanofluids." Renewable and Sustainable Energy Reviews 77 (2017): 551-565. https://doi.org/10.1016/i.rser.2017.04.040

[6] Sajid, Muhammad Usman, and Hafiz Muhammad Ali. "Thermal conductivity of hybrid nanofluids: a critical review." International Journal of Heat and Mass Transfer $126 \quad$ (2018): $211-234$. https://doi.org/10.1016/j.ijheatmasstransfer.2018.05.021

[7] Suresh, S., K. P. Venkitaraj, P. Selvakumar, and M. Chandrasekar. "Synthesis of Al2O3-Cu/water hybrid nanofluids using two step method and its thermo physical properties." Colloids and Surfaces A: Physicochemical and Engineering Aspects 388, no. 1-3 (2011): 41-48. https://doi.org/10.1016/i.colsurfa.2011.08.005

[8] Devi, SP Anjali, and S. Suriya Uma Devi. "Numerical investigation of hydromagnetic hybrid Cu-Al2O3/water nanofluid flow over a permeable stretching sheet with suction." International Journal of Nonlinear Sciences and Numerical Simulation 17, no. 5 (2016): 249-257. https://doi.org/10.1515/ijnsns-2016-0037

[9] Takabi, Behrouz, and Saeed Salehi. "Augmentation of the heat transfer performance of a sinusoidal corrugated enclosure by employing hybrid nanofluid." Advances in Mechanical Engineering 6 (2014): 147059. https://doi.org/10.1155/2014/147059

[10] Xu, Hang. "Modelling unsteady mixed convection of a nanofluid suspended with multiple kinds of nanoparticles between two rotating disks by generalized hybrid model." International Communications in Heat and Mass Transfer 108 (2019): 104275. https://doi.org/10.1016/j.icheatmasstransfer.2019.104275

[11] Khashi'ie, Najiyah Safwa, Norihan M. Arifin, and Ioan Pop. "Unsteady axisymmetric flow and heat transfer of a hybrid nanofluid over a permeable stretching/shrinking disc." International Journal of Numerical Methods for Heat \& Fluid Flow 31, no. 6 (2021): 2005-2021. https://doi.org/10.1108/HFF-07-2020-0421

[12] Khashi'ie, Najiyah S., Norihan M. Arifin, loan Pop, and Nur S. Wahid. "Effect of suction on the stagnation point flow of hybrid nanofluid toward a permeable and vertical Riga plate." Heat Transfer 50, no. 2 (2021): 1895-1910. https://doi.org/10.1002/htj.21961

[13] Lund, Liaquat Ali, Zurni Omar, Ilyas Khan, and El-Sayed M. Sherif. "Dual solutions and stability analysis of a hybrid nanofluid over a stretching/shrinking sheet executing MHD flow." Symmetry 12, no. 2 (2020): 276. https://doi.org/10.3390/sym12020276

[14] Lund, Liaquat Ali, Zurni Omar, Ilyas Khan, Asiful H. Seikh, El-Sayed M. Sherif, and Kottakkaran Sooppy Nisar. "Stability analysis and multiple solution of $\mathrm{Cu}-\mathrm{Al}_{2} \mathrm{O}_{3} / \mathrm{H}_{2} \mathrm{O}$ nanofluid contains hybrid nanomaterials over a shrinking surface in the presence of viscous dissipation." Journal of Materials Research and Technology 9, no. 1 (2020): 421432. https://doi.org/10.1016/i.jmrt.2019.10.071

[15] Zainal, Nurul Amira, Roslinda Nazar, Kohilavani Naganthran, and loan Pop. "Unsteady three-dimensional MHD nonaxisymmetric Homann stagnation point flow of a hybrid nanofluid with stability analysis." Mathematics 8 , no. 5 (2020): 784. https://doi.org/10.3390/math8050784

[16] Zainal, Nurul Amira, Roslinda Nazar, Kohilavani Naganthran, and Ioan Pop. "Unsteady stagnation point flow of hybrid nanofluid past a convectively heated stretching/shrinking sheet with velocity slip." Mathematics 8 , no. 10 (2020): 1649. https://doi.org/10.3390/math8101649

[17] Wahid, Nur Syahirah, Norihan Md Arifin, Najiyah Safwa Khashi'ie, and loan Pop. "Hybrid nanofluid slip flow over an exponentially stretching/shrinking permeable sheet with heat generation." Mathematics 9, no. 1 (2021): 30. https://doi.org/10.3390/math9010030

[18] Ghalambaz, Mohammad, Natalia C. Roşca, Alin V. Roşca, and loan Pop. "Mixed convection and stability analysis of stagnation-point boundary layer flow and heat transfer of hybrid nanofluids over a vertical plate." International Journal of Numerical Methods for Heat \& Fluid Flow 30, no. 7 (2019): 3737-3754. https://doi.org/10.1108/HFF-08$\underline{2019-0661}$

[19] Roşca, Natalia C., Alin V. Roşca, Amin Jafarimoghaddam, and loan Pop. "Cross flow and heat transfer past a permeable stretching/shrinking sheet in a hybrid nanofluid." International Journal of Numerical Methods for Heat \& Fluid Flow 31, no. 4 (2020): 1295-1319. https://doi.org/10.1108/HFF-05-2020-0298

[20] Waini, Iskandar, Anuar Ishak, and Ioan Pop. "Hybrid nanofluid flow past a permeable moving thin needle." Mathematics 8, no. 4 (2020): 612. https://doi.org/10.3390/math8040612

[21] Waini, Iskandar, Anuar Ishak, and Ioan Pop. "Hybrid nanofluid flow and heat transfer past a vertical thin needle with prescribed surface heat flux." International Journal of Numerical Methods for Heat \& Fluid Flow 29, no. 12 (2019): 4875-4894. https://doi.org/10.1108/HFF-04-2019-0277

[22] Salleh, Siti Nur Alwani, Norfifah Bachok, Fadzilah Md Ali, and Norihan Md Arifin. "Flow and Wall Heat Transfer due to a Continuously Moving Slender Needle in Hybrid Nanofluid with Stability Analysis." Journal of Advanced Research in Fluid Mechanics and Thermal Sciences 76, no. 3 (2020): 62-74. https://doi.org/10.37934/arfmts.76.3.6274 
[23] Salleh, Siti Nur Alwani, Norfifah Bachok, Norihan Md Arifin, and Fadzilah Md Ali. "Effect of Buoyancy Force on The Flow and Heat Transfer Around a Thin Needle in AlO-Cu23 Hybrid Nanofluid." CFD Letters 12, no. 1 (2020): 22-36. https://doi.org/10.3390/sym12071176

[24] Waini, Iskandar, Anuar Ishak, and Ioan Pop. "Hybrid nanofluid flow towards a stagnation point on a stretching/shrinking cylinder." Scientific Reports 10, no. 1 (2020): 1-12. https://doi.org/10.1038/s41598-02066126-2

[25] Waini, Iskandar, Anuar Ishak, and loan Pop. "Hybrid nanofluid flow on a shrinking cylinder with prescribed surface heat flux." International Journal of Numerical Methods for Heat \& Fluid Flow 31, no. 6 (2021): 1987-2004. https://doi.org/10.1108/HFF-07-2020-0470

[26] Khashi'ie, Najiyah Safwa, Norihan Md Arifin, Ezad Hafidz Hafidzuddin, and Nadihah Wahi. "Thermally stratified flow of Cu-Al2O3/water hybrid nanofluid past a permeable stretching/shrinking circular cylinder." Journal of Advanced Research in Fluid Mechanics and Thermal Sciences 63, no. 1 (2019): 154-163.

[27] Khashi'ie, Najiyah Safwa, Iskandar Waini, Nurul Amira Zainal, Khairum Hamzah, and Abdul Rahman Mohd Kasim. "Hybrid nanofluid flow past a shrinking cylinder with prescribed surface heat flux." Symmetry 12, no. 9 (2020): 1493. https://doi.org/10.3390/sym12091493

[28] Khashi'ie, Najiyah Safwa, Ezad Hafidz Hafidzuddin, Norihan Md Arifin, and Nadihah Wahi. "Stagnation point flow of hybrid nanofluid over a permeable vertical stretching/shrinking cylinder with thermal stratification effect." CFD Letters 12, no. 2 (2020): 80-94.

[29] Khashi'ie, Najiyah Safwa, Norihan Md Arifin, Roslinda Nazar, Ezad Hafidz Hafidzuddin, Nadihah Wahi, and loan Pop. "Magnetohydrodynamics (MHD) axisymmetric flow and heat transfer of a hybrid nanofluid past a radially permeable stretching/shrinking sheet with Joule heating." Chinese Journal of Physics 64 (2020): 251-263. https://doi.org/10.1016/i.cjph.2019.11.008

[30] Basha, H. Thameem, R. Sivaraj, and Isaac L. Animasaun. "Stability Analysis on Ag-MgO/Water Hybrid Nanofluid Flow Over an Extending/Contracting Riga Wedge and Stagnation Point." Computational Thermal Sciences: An International Journal 12, no. 6 (2020): 491-508. https://doi.org/10.1615/ComputThermalScien.2020034373

[31] Wahid, Nur Syahirah, Norihan Md Arifin, Najiyah Safwa Khashi'ie, Ioan Pop, Norfifah Bachok, and Mohd Ezad Hafidz Hafidzuddin. "Flow and heat transfer of hybrid nanofluid induced by an exponentially stretching/shrinking curved surface." Case Studies in Thermal Engineering 25 (2021): 100982. https://doi.org/10.1016/i.csite.2021.100982

[32] Oztop, Hakan F., and Eiyad Abu-Nada. "Numerical study of natural convection in partially heated rectangular enclosures filled with nanofluids." International Journal of Heat and Fluid Flow 29, no. 5 (2008): 1326-1336. https://doi.org/10.1016/j.ijheatfluidflow.2008.04.009

[33] Merkin, J. H. "On dual solutions occurring in mixed convection in a porous medium." Journal of Engineering Mathematics 20, no. 2 (1986): 171-179. https://doi.org/10.1007/BF00042775

[34] Weidman, P. D., D. G. Kubitschek, and A. M. J. Davis. "The effect of transpiration on self-similar boundary layer flow over moving surfaces." International Journal of Engineering Science 44, no. 11-12 (2006): $730-737$. https://doi.org/10.1016/j.ijengsci.2006.04.005

[35] Harris, S. D., D. B. Ingham, and I. Pop. "Mixed convection boundary-layer flow near the stagnation point on a vertical surface in a porous medium: Brinkman model with slip." Transport in Porous Media 77, no. 2 (2009): $267-285$. https://doi.org/10.1007/s11242-008-9309-6 